Full Length Article

\title{
Knowledge, perceptions and practices of pharmacovigilance amongst community and hospital pharmacists in a selected district of North West Province, South Africa
}

\author{
M.C. Joubert ${ }^{a}$, Panjasaram Naidoo ${ }^{b, *}$ \\ a Pharmasoft Research, Wilkoppies Informal, North West, South Africa \\ ${ }^{\mathrm{b}}$ University of KwaZulu Natal, School of Health Science, Discipline of Pharmaceutical Sciences, Private Bag X54001, \\ Durban, 4001, KZN, South Africa
}

\section{A R T I C L E I N F O}

Article history:

Received 23 October 2015

Accepted 25 April 2016

Available online 6 July 2016

Keywords:

Pharmacovigilance

Pharmacists

Knowledge

Practices

Perceptions

Adverse drug reaction (ADR)

\begin{abstract}
A B S T R A C T
Background: Pharmacovigilance (PV) as a means of ensuring drug safety is an essential component of the process ensuring that the risk of drug use does not outweigh the benefit. Pharmacists are valuable in collecting PV information, but not many studies explored the knowledge, perceptions and practices of both community and hospital pharmacists towards the practice of PV.

Objectives: The aim of the study was to explore the knowledge, perceptions and practise of PV amongst the pharmacists in a selected district of North West Province, South Africa.

Method: A cross sectional study was conducted amongst pharmacists in a selected district of the North West province, using a pre-tested questionnaire. Descriptive statistics were used to analyse the results including ANOVA testing.

Results: One hundred and two pharmacists (68.9\%) completed the questionnaire. Although familiar with the concept of PV, pharmacists knowledge scores were low. Pharmacists agreed that PV is a useful tool, but perceived the PV authorities to be distant and remote. Although more than $90 \%$ indicated that all adverse drug reactions should be reported, only $44.1 \%$ indicated that they have reported adverse drug reactions (ADRs). Only $6.7 \%$ of pharmacists were satisfied with feedback received from authorities after reporting an ADR. Barriers were cited that prevented them from reporting ADRs. Over $80 \%$ indicated they would participate in further PV training.

Conclusion: The majority of pharmacists are familiar with the concept of PV, but less than half reported any ADR. They are willing to participate in PV processes but are unsure what their exact role playing should be. More than half indicated that they would like to see improvements to the current PV system in South Africa. The majority are prepared to undergo further education to improve their PV knowledge.
\end{abstract}

(C) 2016 The Authors. Publishing services by Elsevier B.V. on behalf of Johannesburg University. This is an open access article under the CC BY-NC-ND license (http://

creativecommons.org/licenses/by-nc-nd/4.0/).

\footnotetext{
* Corresponding author.

E-mail addresses: admin@rhino.za.net (M.C. Joubert), naidoopj@ukzn.ac.za (P. Naidoo).

Peer review under responsibility of Johannesburg University.

http://dx.doi.org/10.1016/j.hsag.2016.04.005

1025-9848/@ 2016 The Authors. Publishing services by Elsevier B.V. on behalf of Johannesburg University. This is an open access article under the CC BY-NC-ND license (http://creativecommons.org/licenses/by-nc-nd/4.0/).
} 


\section{Introduction}

Adverse drug reactions (ADRs) are a significant cause of morbidity and mortality worldwide (WHO, 2002). It is an important and sometimes avoidable cause for hospital admissions, adding to the social and financial burden of healthcare (Patel, Bell, \& Molokhia, 2007). In Europe ADRs are responsible for $5 \%$ of all hospital admissions causing on average 1.91 extra hospital days (Montanari-Vergallo, 2013). In the USA, ADRs are among the top 10 leading causes of death (Montanari-Vergallo, 2013). Over a 10 year period (1999-2009) the number of hospital admissions associated with ADRs in England increased by 76.8\% (Wu et al., 2010).

In a South African study, hospital admissions because of ADRs were found to be $6.3 \%$ and $41 \%$ of these developed while the patients were in hospital. Many of the ADRs (46.2\%) were considered preventable. The median hospital stay of patients because of ADRs was 5 days, placing a substantial additional burden on the healthcare system (Mehta et al., 2008).

Managing ADRs are done by applying the science and principles of the discipline of pharmacovigilance (PV). The World Health Organisation (WHO) initially defined PV as the science and activities relating to the detection, assessment, understanding and prevention of adverse effects or any other possible drug related problem (WHO, 2004). The definition has since been extended to include all aspects of medicine development, manufacturing, registration, warehousing, logistics, prescribing, dispensing, use and the destruction of expired medicine stock - spanning the complete product life cycle. Many countries, notably in Europe and the USA, formalised PV risk-benefit legislation to be enforced by their medicine regulatory authorities (Montanari-Vergallo, 2013).

All effects and interactions of medicine, including ADRs, cannot be detected during pre-marketing clinical trials because of the minimal number of patient exposure, lack of long term use, existence of co-morbid conditions, diversity of patient populations and concomitant use of a wide variety of other medications, herbs and foods (Smith, Wertheimer, \& Fincham, 2013). Post-marketing surveillance and continuous PV processes are therefore essential to monitor effects of medicine, ensuring the safe use of medicine.

\section{Key concepts}

\subsection{Spontaneous reporting}

This is reporting an ADR by any healthcare professional, including patients, relatives and others, "spontaneously" as it was observed. A spontaneous report is an unsolicited communication by healthcare professionals or consumers that describes one or more ADR in a patient who was given one or more medicinal product. Spontaneous reporting, also called individual case safety reports (ICSR), is the most common method of medicine surveillance worldwide. ICSRs play a major role in the identification of signals of risk once a medication is used. It may also be possible to recognise a new risk factor for a product or as a sub-group of patients at particular risk (WHO, 2009).
The main limitation of spontaneous reporting is underreporting of ADRs. As in most countries, spontaneous reporting is voluntary and unpaid without specific target goals. However, the main purpose is not the quantification of the frequency of adverse reactions, but the identification of signals (WHO, 2009). Studies indicated that various barriers exist that hinder persons to report ADRs (Zollezzi \& Parsotam, 2005).

\subsection{Cohort event monitoring (CEM)}

This is a prospective, observational, cohort study of adverse events associated with one or more medicines. It is normally recommended that a cohort of 10,000 patients be enrolled giving a $95 \%$ chance of identifying a specific event that has an incidence of CI:3000. For a meaningful assessment, at least three events need to be identified, hence the higher objective to include 10,000 patients (WHO, 2009). Where available, CEM is often combined with Prescription Event Monitoring (PEM), for example the Intensive Medicines Monitoring Programme in New Zealand and the Prescription Event Monitoring in the UK and Japan. PEM is a system where the pharmacists, after dispensing the medication of interest, reports the patient details to a PV centre who then contacts the patient or physician regarding the patient-experience with the medicine (Pal, Duncombe, Falzon, \& Olsson, 2013).

\subsection{Targeted spontaneous reporting (TSR)}

This is where all the patients are monitored when and where the medicine of interest is dispensed. For instance, where patients receive treatment changes for drug-resistant TB or switching from first-line to second-line antiretroviral therapy, the pharmacists is sensitised to be cognitive for the occurrences of ADRs. The advantage of TSR is that an ADR can be identified sooner and the patient is referred for treatment immediately (Pal et al., 2013).

Reporting by consumers have also been allowed by many countries.

\section{Purpose, aims and objectives}

\subsection{Importance of pharmacists}

Pharmacists have a central role in drug safety by contributing to the prevention, identification, documentation, and reporting of ADRs (Zollezzi \& Parsotam, 2005).

Pharmacists do not have the same clinical experience as physicians but are capable of reporting ADRs on their own. Indeed, over a 10 year period, pharmacists reported $31 \%$ of all ADRs in a Portuguese study (Marques, Ribeiro-Vaz, Costa Pereira, \& Polónia, 2013). In many other countries, especially the Netherlands, pharmacists report a substantial number of ADRs (Van Grootheest, 2003).

Communicating effective risk information back to healthcare workers is the result of a successful PV process. A major step in the prevention of ADRs is to ensure that all healthcare workers are informed about the change in the risk-benefit profile of the medicine (Van Grootheest, 2003). 
Pharmacies can also act as a PV hub. They can be a location to keep the report forms, have resources to send completed forms to the nearest PV centre provide a receiving postal address for any information, newsletter or "Dear Dr letter" regarding the safety of medicine. This administrative role is vital in keeping the PV process functioning (Van Grootheest, 2003).

South Africa has a very high HIV and Tuberculosis infection rate. In 2007, with less than $1 \%$ of the world's population, South Africa had $17 \%$ of the global HIV burden and one of the world's worst tuberculosis epidemics, including drugresistance tuberculosis. Malaria infections are also a cause for alarm (Karim, Churchyard, Karim, \& Lawn, 2009). Although there are chemical agents to combat these infections, the therapy is more often disrupted by ADRs causing therapy changes and diminished patient compliance (Chowers et al., 2009).

However, to meet these health challenges, pharmacists can be deployed to assist in monitoring the safe and effective use of available medicine, which certainly includes the management of ADRs. Pharmacists are valuable in collecting PV information, but not many studies explored the knowledge, perceptions and practices of both community and hospital pharmacists towards the practice of PV.

Hence the aim of this study was to examine the knowledge, perceptions and practices of PV among community and hospital pharmacists in a selected district of North West Province, South Africa.

\section{Materials and methods}

\subsection{Study design, population}

A descriptive cross sectional study was conducted over a period of 4 months from March to June 2013. The South African Pharmacy Council database and SA Telkom telephone directory was used to access contact details of all community and hospital pharmacists practising in the Kenneth Kaunda district of the North West province. A total of 148 pharmacists were identified.

\subsection{Instrument}

A coded, anonymous questionnaire was developed containing mostly closed ended questions with the exception of the last question where pharmacists were invited to describe their PV experiences or opinions in their own words. Two sets of double negative questions were included to cross check correct knowledge and attitude questions. The other questions were grouped under the following headings: Demographics, Knowledge, Perceptions, Practice and Barriers. An on-line equivalent of the questionnaire was programmed by the researcher and hosted @ http://www.pcv.za.org/. In the online questionnaire, 2 questions were added aiming to verify the respondent as being a pharmacists.

\subsection{Ethical consideration}

Ethics approval was obtained from the University of KwaZuluNatal-ethics number HSS/1285/012M.

\section{Data collection, capture and analysis}

The questionnaire was administered to the pharmacists after obtaining their consent. Pharmacists were informed of the purpose, benefits and risks of the study, as well as their right to withdraw at any stage. There was no interaction between the participants and the researchers after the procedure had been explained.

For analysis purposes 4 groups of pharmacists were identified depending on the place of work namely: Public or Private Sector, Hospital or Community Pharmacy.

The collected data was entered onto a MS Excel spread sheet and then analysed using the IBM Statistical Package for Social Sciences (SPSS) version 21.0 with a $p<0.05$ indicating statistical significance. Frequency tables with bar charts were used to describe responses to categorical questions while scores were summarised using mean, standard deviation and range. ANOVA (analysis of variance) testing was used to compare mean scores between the four groups of respondents.

\section{Results and findings}

One hundred and two of the 148 pharmacists completed the questionnaires, giving a response rate of $68.9 \%$. The reason why the researcher could not achieve a $100 \%$ participation was refusal by pharmacists to participate or employer refusal for pharmacists to participate. The other reasons were of a logistical or unknown nature.

\subsection{Demographic collection}

The majority $(>90)$ of the respondents graduated from the local university of North West Province. Almost all pharmacists (>95\%) were employed full time with $27.5 \%$ being selfemployed. Other demographic and professional details of respondents are shown in Table 1.

\subsection{Knowledge of pharmacovigilance (6 questions)}

The results on the knowledge questions are depicted in Fig. 1. The knowledge scores ranged from 0 to $92 \%$ with a mean of $42 \%$ and a standard deviation of $22 \%$. There was a large range in knowledge score and the average level of knowledge was low. The highest knowledge score was in the private community pharmacies, followed by the public hospital pharmacies and lowest in the private hospital pharmacies. However the difference in knowledge between the groups was not statistically significant $(p=0.199)$.

\subsection{Attitude and perceptions (11 questions)}

Responses to individual perception questions are shown below in Table 2. Although PV is regarded as a useful tool, reporting pathways to the national PV centres are virtual and remote (Medicine Control Council 61.8\%, NADEMC 55.9\%).

Most pharmacists take responsibility for the risk associated with the medicine they dispense (79.4\%) and indicated 
Table 1 - Demographic and professional information of participants.

\begin{tabular}{llrr} 
Category & & $\mathrm{N}$ & $\mathrm{N} \%$ \\
\hline Participants & & 102 & $100.00 \%$ \\
Gender & Male & 39 & $38.20 \%$ \\
Age group & Female & 63 & $61.80 \%$ \\
& $20-30$ & 30 & $29.40 \%$ \\
& $31-40$ & 29 & $28.40 \%$ \\
& $41-50$ & 22 & $21.60 \%$ \\
Sector & $51-60$ & 9 & $8.80 \%$ \\
Pharmacy type & $61-70$ & 12 & $11.80 \%$ \\
& Private & 49 & $48.00 \%$ \\
Qualification & Public & 53 & $52.00 \%$ \\
& Community & 44 & $43.10 \%$ \\
Management & Hospital & 58 & $56.90 \%$ \\
& B Pharm & 81 & $79.41 \%$ \\
& Post Graduate & 21 & $20.59 \%$ \\
& Pharmacists & 80 & $78.40 \%$ \\
& Responsible & 22 & $21.60 \%$ \\
\hline
\end{tabular}

that all ADR's should be reported on all medicine (old medicine $90.2 \%$, new medicine $91.2 \%$ ).

Most pharmacists receive PV notifications by manufactures $(73.5 \%)$ and $60.8 \%$ indicated that sufficient information is supplied to them.

\subsection{Practices and activities (10 questions)}

Responses to individual practice and activity questions are listed in Table 3. Forty Five (44.1\%) respondents indicated that they did report an ADR. This correlates with the number of

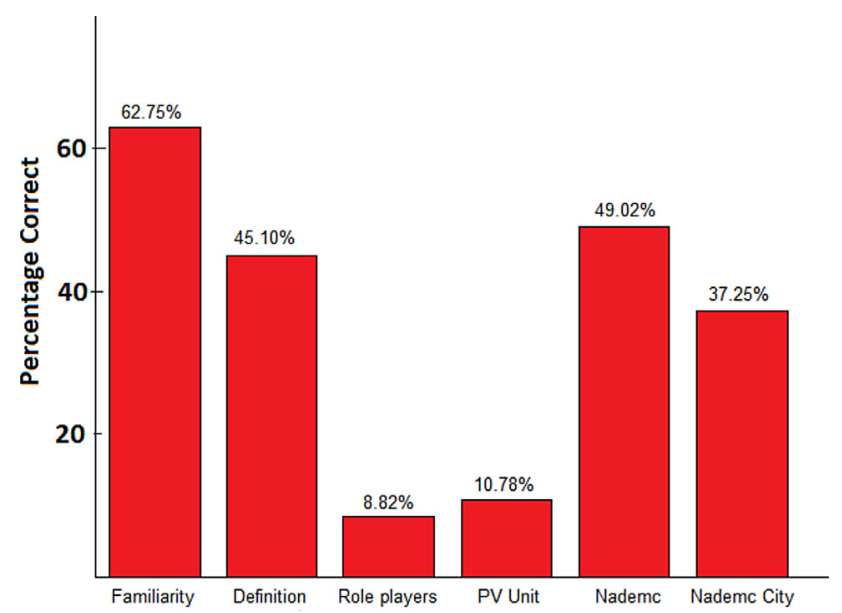

Fig. 1 - Percentage of correct answers for knowledge questions. In the above figure, each of the variables used corresponded to the following question in the surveyed questionnaire. 1) Familiarity - "Are you familiar with the term Pharmacovigilance (PV) ?". 2) Definition - "Please define Pharmacovigilance"? 3) Role players - "Who should participate in Pharmacovigilance activities?”. 4) PV Unit "Where is the seat of the National South African Pharmacovigilance unit?". 5) Nademc - "What does Nademc stand for? (National Adverse Drug Event Monitoring Centre)". 6) Nademc City - "In what city does Nademc operate from?".
Table 2 - Responses to questions on attitude and perceptions.

\begin{tabular}{|c|c|c|c|}
\hline Question & & $\mathrm{N}$ & $\mathrm{N} \%$ \\
\hline Participants & & 102 & $100.00 \%$ \\
\hline \multirow[t]{4}{*}{ PV unrealistic tool } & Yes & 9 & $8.8 \%$ \\
\hline & No & 81 & $79.4 \%$ \\
\hline & Unfamiliar & 6 & $5.9 \%$ \\
\hline & Not answered & 6 & $5.90 \%$ \\
\hline \multirow[t]{4}{*}{ MCC is remote } & Yes & 63 & $61.80 \%$ \\
\hline & No & 27 & $26.5 \%$ \\
\hline & Unfamiliar & 5 & $4.9 \%$ \\
\hline & Not answered & 7 & $6.9 \%$ \\
\hline \multirow[t]{4}{*}{ NADEMC is remote } & Yes & 57 & $55.9 \%$ \\
\hline & No & 22 & $21.6 \%$ \\
\hline & Unfamiliar & 13 & $12.7 \%$ \\
\hline & Not answered & 10 & $9.8 \%$ \\
\hline \multirow[t]{4}{*}{ Medicine risk } & Yes & 82 & $80.4 \%$ \\
\hline & No & 12 & $11.8 \%$ \\
\hline & Unfamiliar & 1 & $1.0 \%$ \\
\hline & Not answered & 7 & $6.9 \%$ \\
\hline \multirow[t]{4}{*}{ Not responsible } & Yes & 7 & $6.9 \%$ \\
\hline & No & 92 & $90.2 \%$ \\
\hline & Unfamiliar & 0 & $0.0 \%$ \\
\hline & Not answered & 3 & $2.9 \%$ \\
\hline \multirow{4}{*}{$\begin{array}{l}\text { Do not report on } \\
\text { ADR if unlisted }\end{array}$} & Yes & 10 & $9.8 \%$ \\
\hline & No & 88 & $86.3 \%$ \\
\hline & Unfamiliar & 0 & $0.0 \%$ \\
\hline & Not answered & 4 & $3.9 \%$ \\
\hline \multirow{4}{*}{$\begin{array}{l}\text { Do not report on } \\
\text { older medicine }\end{array}$} & Yes & 6 & $5.9 \%$ \\
\hline & No & 92 & $90.2 \%$ \\
\hline & Unfamiliar & 1 & $1.0 \%$ \\
\hline & Not answered & 3 & $2.9 \%$ \\
\hline \multirow{4}{*}{$\begin{array}{l}\text { Do not report on } \\
\text { rare ADRs }\end{array}$} & Yes & 6 & $5.9 \%$ \\
\hline & No & 93 & $91.2 \%$ \\
\hline & Unfamiliar & 0 & $0.0 \%$ \\
\hline & Not answered & 3 & $2.9 \%$ \\
\hline \multirow[t]{4}{*}{ Receive 'Dear Dr' letters } & Yes & 75 & $73.5 \%$ \\
\hline & No & 24 & $23.50 \%$ \\
\hline & Unfamiliar & 0 & $0.0 \%$ \\
\hline & Not answered & 3 & $2.9 \%$ \\
\hline \multirow{4}{*}{$\begin{array}{l}\text { Letter info is of } \\
\text { good quality }\end{array}$} & Yes & 62 & $60.8 \%$ \\
\hline & No & 30 & $29.4 \%$ \\
\hline & Unfamiliar & 1 & $1.0 \%$ \\
\hline & Not answered & 9 & $8.8 \%$ \\
\hline \multirow[t]{4}{*}{ Letter info is clear } & Yes & 82 & $80.4 \%$ \\
\hline & No & 11 & $10.8 \%$ \\
\hline & Unfamiliar & 0 & $0.0 \%$ \\
\hline & Not answered & 9 & $8.8 \%$ \\
\hline \multicolumn{4}{|c|}{$\begin{array}{l}\text { PV: Pharmacovigilance. } \\
\text { MCC: Medicines Control Council of South Africa. } \\
\text { NADEMC: National Adverse Drug Event Monitoring Centre. } \\
\text { ADR: Adverse drug reaction. }\end{array}$} \\
\hline
\end{tabular}

respondents that entered a positive value in the "Report time after ADR" question.

The response of $36.3 \%$ (37/102) to the question "Number of ADRs reported" (any number of reports) gave a mean of $41.5 \%$ report activity across all the ADR report questions. On the question of feedback, the overall score was very low $(<20 \%)$ identifying feedback as a problem. Thirty nine of the forty seven (83\%) respondents who managed an ADR, had a successful intervention with $17 \%$ being unsuccessful. More than $50 \%$ of the respondents were not satisfied with the South African PV system. 


\section{Barriers for not reporting ADRs}

Responses to the questions on barriers are depicted in Fig. 2.

It can be seen from this graph that $50 \%$ found reporting to be time consuming whilst over $38 \%$ and $35 \%$ indicated that they do not know how to report or where to report respectively. A percentage of the respondents (12.75\%) did not report because they felt that the ADR were not of a serious nature.

\section{Discussion}

\subsection{Response rate}

The response rate of $68.9 \%$ was found to be consistent and comparable to studies done in other countries (Oreagba,

\begin{tabular}{|c|c|c|c|}
\hline Question & & $\mathrm{N}$ & N\% \\
\hline Participants & & 102 & $100.00 \%$ \\
\hline \multirow{3}{*}{$\begin{array}{l}\text { Reported an adverse } \\
\text { drug reaction }\end{array}$} & Yes & 45 & $44.1 \%$ \\
\hline & No & 56 & $54.9 \%$ \\
\hline & Not answered & 1 & $1.0 \%$ \\
\hline \multirow{6}{*}{$\begin{array}{l}\text { Reported time after } \\
\text { adverse drug reaction }\end{array}$} & Immediately & 19 & $18.6 \%$ \\
\hline & Within days & 16 & $15.7 \%$ \\
\hline & Within weeks & 5 & $4.9 \%$ \\
\hline & Within months & 3 & $2.9 \%$ \\
\hline & Much later & 2 & $2.0 \%$ \\
\hline & Not answered & 57 & $55.9 \%$ \\
\hline \multirow[t]{7}{*}{ Number of reports } & None & 62 & $60.8 \%$ \\
\hline & $1-10$ & 27 & $26.5 \%$ \\
\hline & $10+$ & 2 & $2.0 \%$ \\
\hline & $20-30$ & 1 & $1.0 \%$ \\
\hline & 40 & 1 & $1.0 \%$ \\
\hline & Many & 6 & $5.9 \%$ \\
\hline & Not sure & 3 & $2.9 \%$ \\
\hline \multirow[t]{3}{*}{ Received feedback } & Yes & 18 & $17.6 \%$ \\
\hline & No & 43 & $42.2 \%$ \\
\hline & Not answered & 41 & $40.2 \%$ \\
\hline \multirow[t]{7}{*}{ Time feedback received } & Same day & 3 & $2.9 \%$ \\
\hline & Days & 3 & $2.9 \%$ \\
\hline & Weeks & 9 & $8.8 \%$ \\
\hline & Months & 1 & $1.0 \%$ \\
\hline & Long time & 1 & $1.0 \%$ \\
\hline & Never & 1 & $1.0 \%$ \\
\hline & Not answered & 84 & $82.40 \%$ \\
\hline \multirow[t]{3}{*}{ Feedback sufficient } & Yes & 17 & $16.7 \%$ \\
\hline & No & 24 & $23.5 \%$ \\
\hline & Not answered & 61 & $59.8 \%$ \\
\hline \multirow{3}{*}{$\begin{array}{c}\text { Managed adverse } \\
\text { drug reaction }\end{array}$} & Yes & 47 & $46.1 \%$ \\
\hline & No & 8 & $7.8 \%$ \\
\hline & Not answered & 47 & $46.1 \%$ \\
\hline \multirow[t]{3}{*}{ Successful intervention } & Yes & 39 & $38.2 \%$ \\
\hline & No & 8 & $7.8 \%$ \\
\hline & Not answered & 55 & $53.9 \%$ \\
\hline \multirow{5}{*}{$\begin{array}{l}\text { Outcome of adverse } \\
\text { drug reaction }\end{array}$} & Death & 3 & $2.9 \%$ \\
\hline & Disability & 3 & $2.9 \%$ \\
\hline & Hospitalisation & 5 & $4.9 \%$ \\
\hline & Other & 7 & $6.9 \%$ \\
\hline & Not answered & 84 & $82.40 \%$ \\
\hline \multirow{3}{*}{$\begin{array}{l}\text { Pharmacovigilance } \\
\text { system in SA }\end{array}$} & Yes & 19 & $18.6 \%$ \\
\hline & No & 52 & $51.0 \%$ \\
\hline & Not answered & 31 & $30.4 \%$ \\
\hline
\end{tabular}

Ogunleye, \& Olayemi, 2011; Toklu \& Uysal, 2008; Van Grootheest, 2003).

\subsection{Demographics}

In this study, age, gender, post-graduate qualification, selfemployment and management role was taken to estimate experience. However, there was no significant correlation between pharmacists experience and knowledge score.

\subsection{Knowledge}

Although $62.8 \%$ of respondents stated that they are familiar with the concept of PV only $46.1 \%$ selected the correct WHO definition of PV. This finding supports the observation that most pharmacists would associate the term PV with "side effects" of medicine but they lack in depth knowledge of ADR and the associated PV processes. Other studies have also found this merging of the terms "side effect" with "adverse drug reaction" (Amrita \& Roomi, 2011).

Only a small percentage of respondents (8.8\%) selected the correct answer that all healthcare workers are role players in the PV process, a finding supported by another study where pharmacists appear misinformed about PV processes (Palaian, Ibrahim, \& Mishra, 2011). It is therefore important to define and communicate the PV function of pharmacists more clearly (Palaian et al., 2011).

An interesting finding in this study was that the knowledge score for community pharmacists was the highest compared to the pharmacists working in the other sectors. This finding is not consistent with many other studies done on PV in other countries where hospital pharmacists knowledge of PV is better than pharmacists in the other sectors (Prakasam, Nidamanuri, \& Kumar, 2012). However the difference in knowledge scores within the groups was not significant in this study.

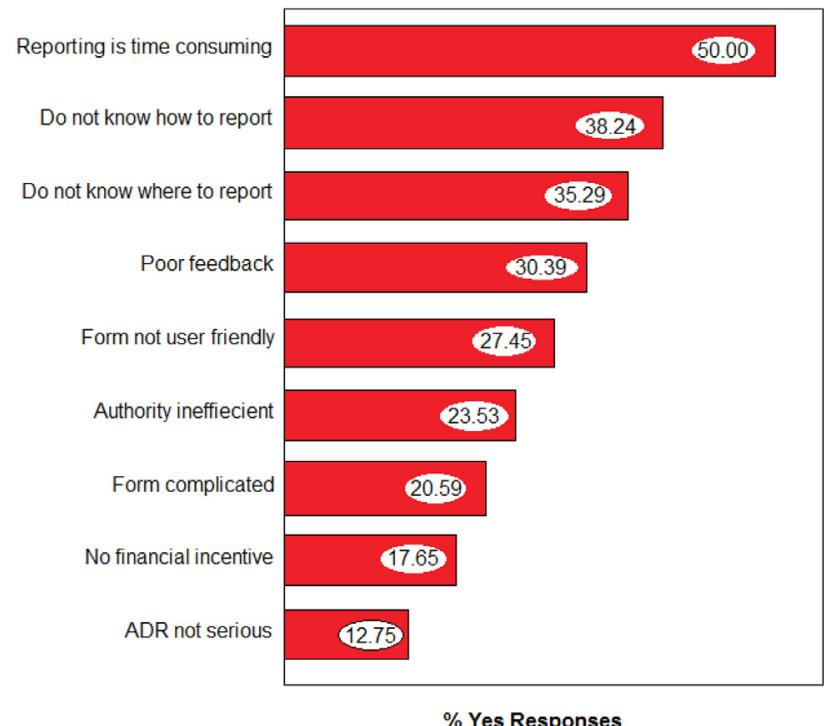

Fig. 2 - Barriers to reporting ADR. 


\subsection{Perceptions and attitudes}

Most respondents (79.4\%) regarded PV as a valuable tool. This response is consistent with other studies that found that pharmacists are very positive about the prospect of working with PV cases (Granas, Buajordet, Stenberg-Nilsen, Harg, \& Horn, 2007).

All respondents expressed the opinion that they would like to see more communication between them and the PV centres. These institutions seem to be unacceptable for pharmacists, therefore pharmacists tend to regard them as virtual and remote with little or no personal contact. A high percentage of the respondents expressed low satisfaction with the SA PV system. This seems to be the case in many African countries where a functional PV system is underdeveloped or absent due to pressing other priorities. Where present in an African country, the PV activities are mostly driven by manual mechanisms of reporting (Kiguba, Karamagi, Waako, \& Bird, 2013).

\subsection{Practice and activities}

Forty five (44.1\%) respondents indicated that they have reported an ADR. Compared to other studies, this is a relative high rate of reporting (Marques et al., 2013; Prakasam et al., 2012). In the South African context there is a greater patient exposure to antiretroviral and anti-malaria products that have a range of toxic effects and are prone to ADRs (Chowers et al., 2009; Karim et al., 2009). This may contribute to the high report rate seen in this study.

It was clear that there was a gap in managing feedback to the reporters. Even though 35 pharmacists reported within days after an ADR was detected, only 6 respondents stated that they got feedback within days. This clearly poses a barrier to pharmacists wanting to participate in PV activities. This minimal feedback is a barrier cited in other PV studies (Van Grootheest, 2003; Zollezzi \& Parsotam, 2005).

\subsection{Barriers}

Some of the barriers cited in this study are consistent with barriers found in similar studies, these include how to report, where to report, where to obtain a form, the reporting form not user friendly and poor feedback, etc (Oreagba et al., 2011; Toklu \& Uysal, 2008; Zollezzi \& Parsotam, 2005).

Though knowledge was not surveyed as a barrier, a study done in the Netherlands amongst community sector pharmacists found that the most frequently reported barrier to not reporting was the assumption that the ADR was known or the uncertainty about the causal relationship between the ADR and a medicine (predisposing factor: knowledge) (Irujo, Figueiras, Hernández-Díaz \& Lasheras, 2007; Van Grootheest, 2003). Poor system wide knowledge about the PV processes could have been a major factor in shaping the answers obtained in this study. The pharmacists $(>80 \%)$ however indicated their willingness to participate in further PV education.

\section{Limitations of the study}

The small sample size $(n=148)$ makes the study not representative of all pharmacists in South Africa $(n>12,000)$ but barely represents the opinion of $1.1 \%$. Because most respondents (>90\%) studied at the local university of the North West Province, the answers might be influenced by the past curriculum of this institution. A question about previous PV training could have been useful to asses answers given by already trained pharmacists and compared it to answers from pharmacists never trained in PV. When answers to knowledge questions are available on the Internet, like in this study, the respondents could have looked up the answer by a variety of means (smart phone, computers, other connected devices) and therefore these questions could be biased by false positive results. It would be advisable for researchers to mitigate this fact in future research.

\section{Conclusion}

It can be concluded that the knowledge scores of pharmacists and their reporting of ADRs are not optimal. The pharmacist expressed their dissatisfaction of the current PV system in South Africa. It therefore stands to reason that the system needs to be strengthened. The pharmacists are willing to participate in PV processes and are prepared to undergo further education and training to improve their PV knowledge and activities. Barriers to participation of pharmacists in PV activities do exist that will have to be addressed.

\section{Recommendation for future research}

The authors recommend a similar study with a larger sample size to be conducted amongst pharmacists, doctors and nurses in South Africa.

\section{Acknowledgements}

The authors would like to thank the pharmacists for their participation, Ms Ronel of the North West Department of Health for organising participation of pharmacist, Ms Tonya Esterhuizen for her statistical support and the College of Health Science, University of KwaZulu Natal for funding the research.

\section{R E F E R E N C E S}

Amrita, P., \& Roomi, M. T. (2011). Scenario of pharmacovigilance and ADR reporting among pharmacists in Delhi. Indian Journal of Pharmacy Practice, 4(4). http://www.ijopp.org/article/60.

Chowers, M. Y., Gottesman, B. S., Leibovici, L., Pielmeier, U., Andreassen, S., \& Paul, M. (2009). Reporting of adverse events in randomized controlled trials of highly active antiretroviral therapy: systematic review. Journal of Antimicrobial Chemotherapy, 64(2), 239-250. http://dx.doi.org/10.1093/jac/ dkp191.

Granas, A., Buajordet, M., Stenberg-Nilsen, H., Harg, P., \& Horn, A. M. (2007). Pharmacists' attitudes towards the reporting of suspected adverse drug reactions in Norway. 
Pharmacoepidemiology and Drug Safety, 16(4). http://dx.doi.org/ 10.1002/pds.1298.

Irujo, M., Beitia, G., Bes-Rastrollo, M., Figueiras, A., HernándezDíaz, S., \& Lasheras, B. (2007). Factors that influence underreporting of uspected adverse drug reactions among community pharmacists in a Spanish region. Drug Safety, 30, 1073-1082. http://www.ncbi.nlm.nih.gov/pubmed/17973543.

Karim, S. A., Churchyard, G. J., Karim, Q. A., \& Lawn, S. D. (2009). HIV infection and tuberculosis in South Africa: an urgent need to escalate the public health response. The Lancet, 374(9693), 921-933. http://dx.doi.org/10.1016/S0140-6736(09)60916-8.

Kiguba, R., Karamagi, C., Waako, P., \& Bird, S. M. (2013). Barriers and facilitators to suspected adverse drug reaction reporting among healthcare professionals in Uganda. In 1st Scientific Conference on medicines regulation in Africa. Johannesburg, South Africa, 3rd December 2013. http://amrh.org/wp-content/ uploads/2014/10/first_biennial_scientific_conference_in Africa_book_of-_abstracts_english.pdf.

Marques, J., Ribeiro-Vaz, I., Costa Pereira, A., \& Polónia, J. (2013). A survey of spontaneous reporting of adverse drug reactions in 10 years of activity in a pharmacovigilance centre in Portugal. International Journal of Pharmacy Practices, 22, 275-282. http:// dx.doi.org/10.1111/ijpp.12078.

Mehta, U., Durrheim, D. N., Blockman, M., Kredo, T., Gounden, R., \& Barnes, K. I. (2008). Adverse drug reactions in adult medical inpatients in a South African hospital serving a community with a high HIV/AIDS prevalence: prospective observational study. British Journal of Clinical Pharmacology, 65(3), 396-406. http://dx.doi.org/10.1111/j.1365-2125.2007.03034.x.

Montanari-Vergallo, G. (2013). Recent developments in EU and US pharmacovigilance legislation. Journal of Pharmacovigilance, 1. e105 http://dx.doi.org/10.4172/2329-6887.1000e105.

Oreagba, I. A., Ogunleye, O. J., \& Olayemi, S. O. (2011). The knowledge, perceptions and practice of pharmacovigilance amongst community pharmacists in Lagos state, south west Nigeria. Pharmacoepidemiology and Drug Safety, 20, 30-35. http://dx.doi.org/10.1002/pds.2021.

Palaian, S., Ibrahim, M. I., \& Mishra, P. (2011). Health professionals' knowledge, attitude and practices towards pharmacovigilance in Nepal. Journal of Pharmacy Practice (Granada), 9(4), 228-235. Oct- Dec http://www.ncbi.nlm.nih. gov/pmc/articles/PMC3818739/.

Pal, S. N., Duncombe, C., Falzon, D., \& Olsson, S. (2013). WHO strategy for collecting safety data in public health programmes: complementing spontaneous reporting systems. Drug Safety, 2013(36), 75-81. http://dx.doi.org/10.1007/s40264012-0014-6. http://dx.doi.org/10.1007/s40264-012-0014-6.
Patel, H., Bell, D., \& Molokhia, M. (2007). Trends in hospital admissions for adverse drug reactions in England: analysis of national hospital episode statistics 1998-2005. BMC Clinical Pharmacology, 7(9). http://dx.doi.org/10.1186/1472-6904-7-9.

Prakasam, A., Nidamanuri, A., \& Kumar, S. (2012). Knowledge, perception and practice of pharmacovigilance among community pharmacists in South India. Pharmacy Practice (Granada), 10(4), 222-226. Oct-Dec; [PMCID: 3780499] http:// www.ncbi.nlm.nih.gov/pmc/articles/PMC3780499/.

Smith, M. I., Wertheimer, A. I., \& Fincham, J. E. (2013). Pharmacy and the US health care system (4th ed, pp. 299-302). London SE1 7JN, UK: Royal Pharmaceutical Society of Great Britain, Pharmaceutical Press, ISBN 9780857110220. Feb 2013. http:// books.google.co.za/books?id=bKiBvV33ir8C.

Toklu, H. Z., \& Uysal, M. K. (2008). The knowledge and attitude of the Turkish community pharmacists toward pharmacovigilance in the Kadikoy district of Istanbul. Pharmacy World \& Science, 30(5), 556-562. http://dx.doi.org/10. 1007/s11096-008-9209-4.

Van Grootheest, A. C. (2003). Improving pharmacovigilance and the role of the pharmacists. http://dissertations.ub.rug.nl/faculties/ science/2003/a.c.van.grootheest/. http://irs.ub.rug.nl/ppn/ 255748183.

World Health Organization. (2002). The World Health Report 2002, safety of medicines - a guide to detecting and reporting adverse drug reactions - Why health professionals need to take action. Geneva: World Health Organization. http://apps.who.int/ medicinedocs/en/d/Jh2992e/12.html.

World Health Organization. (2004). WHO guidelines on safety monitoring of herbal medicines in pharmacovigilance systems. http://apps.who.int/medicinedocs/documents/s7148e/s7148e. pdf.

World Health Organization. (2009). A practical handbook on the pharmacovigilance of antiretroviral medicines. Geneva: World Health Organization, ISBN 978924154794 9. http://www.who. int/medicines/areas/quality_safety/safety_efficacy/ HIVhandbook.pdf.

Wu, T., Jen, M., Bottle, A., Molokhia, M., Aylin, P., Bell, D., et al. (2010). Ten-year trends in hospital admissions for adverse drug reactions in England 1999-2009. Journal of the Royal Society of Medicine, 103, 239. http://dx.doi.org/10.1258/jrsm.2010. 100113.

Zolezzi, M., \& Parsotam, N. (2005). Adverse drug reaction reporting in New Zealand: implications for pharmacists. Therapeutics and Clinical Risk Management, 1(3), 181-188, 2005 Sep. 